\section{BMJ Open Respiratory Research}

\title{
Anaemia and iron dysregulation: untapped therapeutic targets in chronic lung disease?
}

\author{
Mehul S Patel, ${ }^{\oplus 1}$ Elizabeth McKie, ${ }^{1}$ Michael C Steiner, ${ }^{\circ}$ Steven J Pascoe, ${ }^{3}$ \\ Michael I Polkey ${ }^{4}$
}

To cite: Patel MS, McKie E, Steiner MC, et al. Anaemia and iron dysregulation: untapped therapeutic targets in chronic lung disease?. BMJ Open Resp Res 2019;6:e000454. doi:10.1136/ bmjresp-2019-000454

SJP and MIP contributed equally.

Received 4 June 2019 Revised 27 June 2019 Accepted 28 June 2019
D Check for updates

(C) Author(s) (or their employer(s)) 2019. Re-use permitted under CC BY-NC. No commercial re-use. See rights and permissions. Published by BMJ.

${ }^{1}$ R\&D, GlaxoSmithKline, Stevenage, UK

${ }^{2}$ Leicester Biomedical Research Centre - Respiratory, Institute for Lung Health, University of Leicester, Leicester, UK

${ }^{3}$ Sanofi, Bridgewater, New Jersey, USA

${ }^{4}$ National Heart and Lung Institute, Imperial College London, London, UK

Correspondence to Dr Mehul S Patel; mehul.patel1@astrazeneca. com

\section{ABSTRACT}

Hypoxia is common in many chronic lung diseases. Beyond pulmonary considerations, delivery of oxygen $\left(\mathrm{O}_{2}\right)$ to the tissues and subsequent $\mathrm{O}_{2}$ utilisation is also determined by other factors including red blood cell mass and iron status; consequently, disruption to these mechanisms provides further physiological strains on an already stressed system. $\mathrm{O}_{2}$ availability influences ventilation, regulates pulmonary blood flow and impacts gene expression throughout the body. Deleterious effects of poor tissue oxygenation include decreased exercise tolerance, increased cardiac strain and pulmonary hypertension in addition to pathophysiological involvement of multiple other organs resulting in progressive frailty. Increasing inspired $\mathrm{O}_{2}$ is expensive, disliked by patients and does not normalise tissue oxygenation; thus, other strategies that improve $0_{2}$ delivery and utilisation may provide novel therapeutic opportunities in patients with lung disease. In this review, we focus on the rationale and possibilities for doing this by increasing haemoglobin availability or improving iron regulation.

\section{BACKGROUND}

Humans require oxygen $\left(\mathrm{O}_{2}\right)$ delivery to core organs (eg, heart, brain or kidneys) at rest and, when exercising, oxygen must also be delivered to exercising muscle if anaerobic metabolism is to be prevented. Chronic respiratory diseases may impair $\mathrm{O}_{2}$ delivery at multiple levels. For example, in chronic obstructive pulmonary disease (COPD), the problem is often predominantly one of respiratory mechanics, whereas in lung fibrosis, it may be oxygen transport across the alveolar capillary junction. Both these and other conditions may also be associated with pulmonary hypertension and impaired cardiac output, particularly during exercise. Patients with chronic respiratory diseases need to increase respiratory drive ${ }^{1}$ to maintain $\mathrm{O}_{2}$ delivery irrespective of the aetiology of the deficiency, which gives rise to the symptom of breathlessness which in turn leads to reduced physical activity with an adverse effect on quality of life. When disease is sufficiently severe, this effect is common to several different respiratory populations, especially COPD, asthma, pulmonary fibrosis and bronchiectasis.

Delivery of $\mathrm{O}_{2}$ to the tissues is also determined by non-respiratory factors including red blood cell mass, tissue capillarity and cardiac output. Utilisation of $\mathrm{O}_{2}$ also fundamentally drives tissue $\mathrm{O}_{2}$ requirements and iron plays a key role through mediating cellular respiration and energy metabolism (figure 1). Disruption to these mechanisms may trigger a downward cycle in which hypoxia imposes further physiological strains on an already stressed system. Deleterious effects of hypoxia through the multiple downstream effects of poor tissue oxygenation include increased cardiac strain, pulmonary hypertension and salt and water imbalance mediated through the impact of cardiac and circulatory insufficiency (Cor Pulmonale). Pathophysiological secondary damage to multiple other organs and tissues including skeletal muscle, brain, kidney and gut are also attributable to impaired $\mathrm{O}_{2}$ delivery. ${ }^{2}{ }^{3}$ In the setting of relative tissue hypoxia and an imbalance between oxygen demand and respiratory capacity, a 'spiral of decline' ensues resulting in progressive deconditioning, frailty and both enhanced oxygen demand and increased respiratory loading through premature exercise induced acidosis (figure 2). ${ }^{4}$ A multimodal approach to managing patients with chronic lung disease is advocated, ${ }^{5}$ comprising approaches aimed at enhancing respiratory capacity (eg, bronchodilation or lung volume reduction in emphysema) and reducing respiratory demand (such as exercise training). Novel approaches that impact upstream pathophysiological events including impaired tissue oxygen delivery may be expected to provide significant therapeutic benefit. ${ }^{6}$

The availability of $\mathrm{O}_{2}$ is essential for organ viability and function and is subsequently closely regulated at a cellular level and 


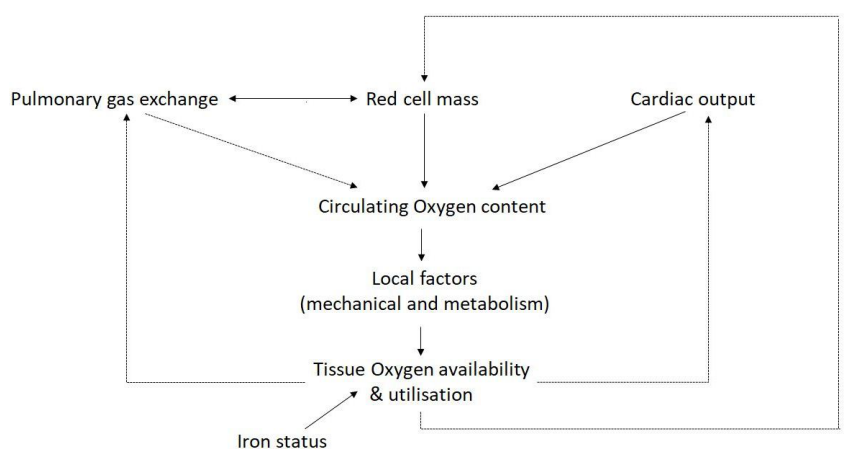

Figure 1 The role of iron and red cell mass in tissue oxygen availability and utilisation.

through integrated physiological responses. Although a significant proportion of subjects with severe lung disease exhibit $\mathrm{O}_{2}$ desaturation at rest, tissue oxygen delivery is further impaired under conditions of strain, for example, exercise $^{7}$ or during exacerbation. It is clear that routine clinical measures of $\mathrm{O}_{2}$ delivery such as fingertip haemoglobin $(\mathrm{Hb})$ oxygen saturation $\left(\mathrm{SpO}_{2}\right)$ may inappropriately provide reassurance and significantly underestimate the degree of impairment of tissue oxygenation. ${ }^{8}$ For example, while approximately half of patients with COPD with resting $\mathrm{SpO}_{2} \leq 95 \%$ desaturate on exertion, an additional $16 \%$ desaturate on exercise despite having resting $\mathrm{SpO}_{2}>95 \% .{ }^{9}$ Furthermore, $38 \%$ of patients with moderate to severe COPD desaturate at night without evidence of obstructive sleep apnoea ${ }^{10}$ due to physiological reduction of neural drive. ${ }^{11}$

$\mathrm{Hb}$, which transports $\mathrm{O}_{2}$ in the blood, has a fundamental role in $\mathrm{O}_{2}$ delivery because the solubility of $\mathrm{O}_{2}$ is low; at a normal partial pressure of oxygen $\left(\mathrm{PaO}_{2}\right)^{2}$ of $13 \mathrm{kPa}$, there is only $3 \mathrm{~mL}$ of dissolved $\mathrm{O}_{2}$ per litre compared with $200 \mathrm{~mL}$ per litre bound to Hb. ${ }^{3}$ Thus, quantitatively, anaemia may have a greater impact on oxygen delivery than reduced $\mathrm{O}_{2}$ saturation (figure 3). Subsequently, tissue $\mathrm{O}_{2}$ availability may be reduced even when $\mathrm{O}_{2}$ content measured by traditional methods, such as $\mathrm{PaO}_{2}$ or $\mathrm{SpO}_{2}$ is adequate.

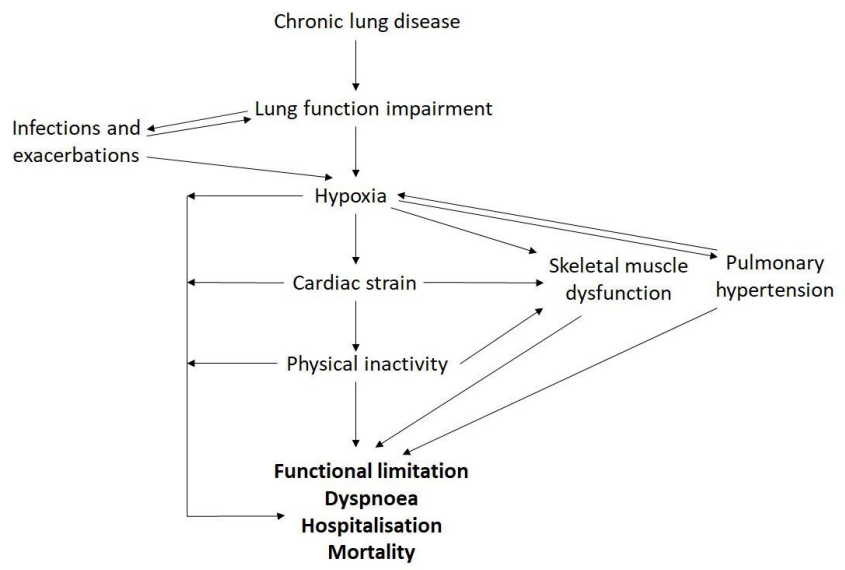

Figure 2 The 'spiral of decline' in chronic lung disease: an interplay between pathophysiological features.

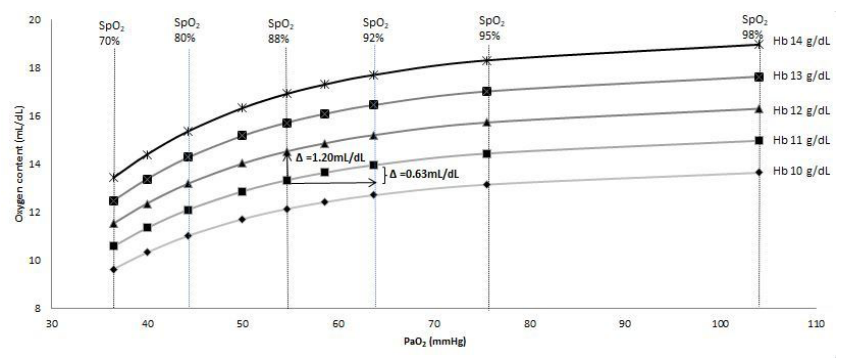

Figure 3 The comparative oxygen content of circulating blood within the setting of physiologically relevant anaemia and reduced $\mathrm{Hb}$ oxygen saturation. In a patient with an $\mathrm{Hb}$ of $11 \mathrm{~g} / \mathrm{dL}$ and oxygen saturations of $88 \%$, increasing the $\mathrm{Hb}$ by $1 \mathrm{~g} / \mathrm{dL}$ has double the impact on oxygen content than improving $\mathrm{Hb}$ oxygen saturation by $4 \%$. Improvements in oxygen content may occur with increased $\mathrm{Hb}$ even in the setting of normal saturations (eg, as may be relevant in concomitant cardiac failure given that oxygen delivery is the product of cardiac output and oxygen content).

It has been shown in COPD that $\mathrm{Hb}$ is directly related to oxygen consumption $\left(\mathrm{VO}_{2}\right.$ max) even after accounting for disease severity ${ }^{12}$ and, at a patient level, symptomatic burden and mortality. ${ }^{13}{ }^{14}$ Indeed $\mathrm{O}_{2}$ availability impacts ventilation, pulmonary blood flow and gene expression throughout the body. ${ }^{2}$ Long-term oxygen therapy (LTOT) is an established therapy that reduces both morbidity ${ }^{15}$ and mortality ${ }^{1617}$ in severely hypoxic patients and, in appropriate populations, supplementing inspired $\mathrm{O}_{2}$ increases exercise duration. ${ }^{18}$ Scenarios where other factors may be more important than traditional measures of oxygenation and consistent with the relevance of $\mathrm{Hb}$ concentration to circulating $\mathrm{O}_{2}$ content (figure 3) include patients with less severe exercise $\mathrm{O}_{2}$ desaturation not benefitting from supplementing inspired oxygen ${ }^{19} 20$ and conflicting data surrounding the impact of $\mathrm{O}_{2}$ supplementation on exercise performance and health-related quality of life (HRQoL). ${ }^{21}$

Despite the benefits of $\mathrm{O}_{2}$ supplementation, even when the recipient is carefully selected, there remain the practical issues in ensuring that inspired $\mathrm{O}_{2}$ is supplemented for the required time ( $>15$ hours a day) to achieve benefit. Furthermore, in some subsets such as ongoing smokers, the risks may actually outweigh the benefits. ${ }^{22}{ }^{23}$ Given the challenges of normalising $\mathrm{O}_{2}$ delivery in patients with established lung disease, other strategies that improve $\mathrm{O}_{2}$ content and metabolism might deliver direct patient benefits and synergise with the benefits of other available therapeutic strategies including oxygen supplementation itself. Thus, increasing $\mathrm{Hb}$ availability represents a novel therapeutic opportunity in this population ${ }^{24}$ with the potential to improve exercise tolerance, dyspnoea, fatigue and HRQoL, and in the longer term, reduce the risk of hospitalisation and mortality (figure 2). Beyond any relevance to erythropoiesis, there is also a potential role for treating dysregulated iron metabolism in chronic lung disease, given a shared pathophysiology, hereon, we 


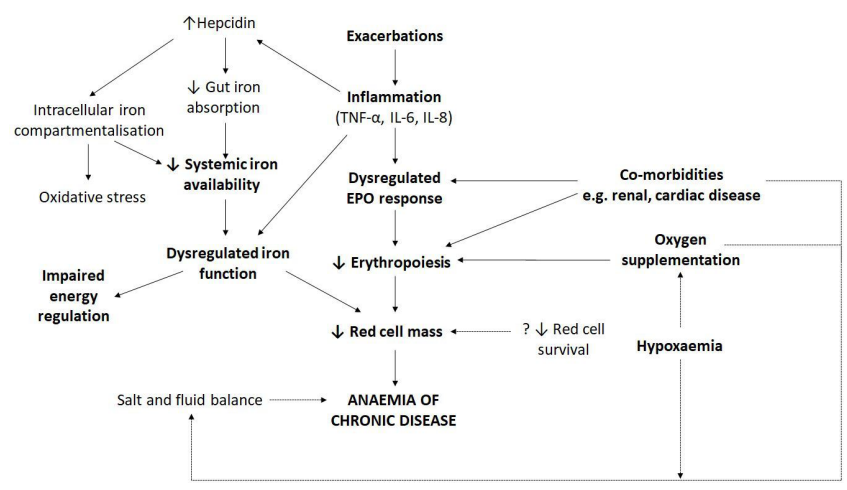

Figure 4 The clinical and biological factors relevant to iron dysregulation and anaemia of chronic disease in respiratory populations. EPO, erythropoietin.

detail the aetiology and relevance of anaemia and functional iron deficiency in respiratory disease.

\section{The clinical relevance of anaemia, inflammation and dysregulated iron metabolism}

Many chronic diseases have been shown to impact haematopoiesis and this is especially relevant in chronic lung disease. Polycythaemia has traditionally been considered an indication for venesection in COPD given the potential risks of hypercoagulability; however, this erythropoietic response is driven by tissue hypoxia and following the institution of LTOT as a standard of care, polycythaemia is now three times less prevalent than anaemia. ${ }^{14}$ In cystic fibrosis (CF), pulmonary arterial hypertension (PAH) and COPD, a significant number of subjects have anaemia and or iron deficiency (circa $20 \%-40 \%),{ }^{142-30}$ although this area is poorly studied and the incidence may be significantly underestimated, since establishing iron deficiency is complicated because of the effects of inflammation on serum iron, transferrin and ferritin. Contextually, a role for functional iron deficiency may be equally relevant as may be disease-specific considerations including propensity to infection. ${ }^{30}$ Although not currently part of routine clinical assessment, serum transferrin receptor levels appear to be unaffected by inflammation and may more accurately reflect iron status in chronic lung disease; circulating levels in the normal range reflect erythropoietic activity and levels are disproportionately elevated in iron deficiency. ${ }^{31}$

In a series that considered this complexity, anaemia of chronic disease or 'anaemia of inflammation', was observed in $10 \%$ of patients with stable COPD. ${ }^{12}$ Congruent with the pathophysiological relevance of inflammation, the prevalence of anaemia in COPD has been observed to be up to $44 \%$ among patients admitted with acute exacerbation ${ }^{25}$ and the presence of anaemia in this scenario is independently associated with mortality. ${ }^{26}$ In fact, anaemia and/or iron deficiency have been consistently shown to have a strong correlation with morbidity ${ }^{12} 2732$ and mortality across several lung diseases, ${ }^{13} 1433-35$ the reported prevalence has been widely variable due to the different characteristics of study populations and the lack of a consensus definition of anaemia in the context of chronic lung disease. While most authors use the WHO definition $(<13 \mathrm{~g} / \mathrm{dL}$ for males and $12 \mathrm{~g} / \mathrm{dL}$ females), some use the same $\mathrm{Hb}$ level for both men and women (since most women are postmenopausal in these populations), while others have used haematocrit as the identifying factor. Although the prevalence also varies across the various respiratory populations, the impact of anaemia in the setting of impaired physiology and symptomatic limitation is expected to be common to a range of respiratory diseases.

Consistent with the physiological relevance of anaemia, several clinical studies in COPD have reported a significant deleterious effect of anaemia on exercise capacity, with anaemic patients being more dyspnoeic and exhibiting functional exercise limitation ${ }^{12} 1436$ and reduced maximal $\mathrm{O}_{2}$ consumption. ${ }^{12}$ In a regression analysis, higher $\mathrm{Hb}$ levels were independently associated with improved exercise capacity and HRQoL. ${ }^{37}$ Improved $\mathrm{Hb}$ is expected to benefit $\mathrm{O}_{2}$ delivery even beyond the lower limit of the normal $\mathrm{Hb}$ range (figure 3 ) and in fact higher Hb levels $(14.3 \mathrm{~g} / \mathrm{dL}$ in females, $15.1 \mathrm{~g} / \mathrm{dL}$ in males) have been shown to be associated with improved survival in patients with chronic respiratory failure. ${ }^{33}$ The performance benefits of elevating $\mathrm{Hb}$ above the physiological range are well established in athletes and this is expected to translate to respiratory patients who are compromised in their ability to establish appropriate ventilatory and cardiac responses to exercise. ${ }^{38}$ Although iron deficiency does not appear to impact viscosity, higher haematocrit has been associated with hyperviscosity in other populations where the association between higher haematocrit and greater exercise capacity is maintained despite this. ${ }^{40}$

\section{Mechanisms of anaemia in chronic lung disease}

The mechanisms leading to anaemia in chronic lung disease are complex and have not yet been fully characterised. Factors pertinent to ageing in general and to other populations appear to be implicated in the process; however, in the context of anaemia of chronic disease, the underlying inflammatory disease and erythropoietin (EPO) response seem the most relevant (figure 4). Inflammation in lung disease is thought to play a major role through both direct and indirect mechanisms. Inflammatory cytokines such as interleukin (IL)-1, IL-6, IL-10, IL-22, interferon- $\gamma$ and tumour necrosis factor $1-\alpha$ interfere with the normal function of several molecules involved in iron metabolism. ${ }^{41}{ }^{42}$ These inflammatory markers are generally increased in anaemic patients with chronic lung disease and are associated with reduced serum iron levels and decreased iron availability for erythropoiesis; ${ }^{3643}$ they are believed to do this through the destruction of red blood cell precursors and decreasing the number of EPO receptors on progenitor cells. ${ }^{44}$ Interestingly, this increase in inflammatory 
cytokines, particularly IL-6, is also considered to be an innate immune response to infection as it reduces iron availability for the growth of extracellular pathogens and is relevant to respiratory populations predisposed to bacterial and viral infections. ${ }^{42}$ Beyond the direct effects on iron metabolism, inflammatory cytokines have been found to strongly influence hepcidin production under conditions of hypoxia. ${ }^{45}$ Hepcidin production is normally reduced in response to hypoxia and anaemia so that erythropoietic iron demands can be fulfilled; however, in chronic inflammatory states, IL-6 induces synthesis and secretion of hepcidin by hepatocytes and consequently reduces extracellular iron availability. ${ }^{46} 47$ These different underlying causes of anaemia conferred by chronic systemic inflammation are seen in a variety of conditions, thus impairing normal corrective mechanisms and they are also relevant in chronic lung disease (figure 4).

Other factors besides inflammation have been described as being relevant in the development of anaemia in chronic lung disease including: (1) renin-angiotensin-aldosterone system dysregulation resulting in reduced erythropoiesis, ${ }^{48} 49$ (2) renal impairment resulting in reduced EPO production and reduced hepcidin clearance, ${ }^{5051}$ (3) theophylline treatment resulting in reduced EPO production and/or direct inhibition of erythroid progenitor cells ${ }^{5253}$ (4) androgen deficiency resulting in reduced erythropoiesis ${ }^{54}$ and (5) malnutrition resulting in iron, vitamin $\mathrm{B}_{12}$ and folic acid deficiencies. ${ }^{556}$ Other factors relevant to general populations such as impaired bone marrow response may also be relevant, especially in COPD and idiopathic pulmonary fibrosis (IPF) which typically occur in older populations. ${ }^{55}$

EPO acts as the primary stimulus for erythropoiesis and is normally produced by the kidneys in response to reduced tissue oxygenation. Renal impairment, which is common in patients with COPD, can lead to disruption in EPO production. However, in COPD, the relationship between hypoxia, inflammation, iron and EPO is complex with studies showing differing results. Non-clinical and clinical evidence suggests that EPO production could be inhibited by the effects of inflammatory cytokines: ${ }^{57}$ however, some clinical studies have also identified mildly increased levels of EPO (circa twofold) in COPD ${ }^{589}$ While upregulation of EPO is expected in the setting of hypoxia, these increased EPO levels in COPD are not necessarily translated to enhanced erythropoiesis. While some have considered this as EPO resistance, in the setting of multiple factors relevant to anaemia in this population, especially inflammation, this may be alternatively considered a relative EPO deficiency (figure 4) $;^{57}$ the levels observed are certainly well below those seen when a functional response occurs-in the setting of erythropoiesis therapeutically driven by exogenous EPO, EPO levels may be 100 s of fold greater. ${ }^{601}$ Consistent with an inadequate EPO response in chronic lung disease, exacerbations which are inherently associated with inflammation and hypoxia, are associated with an increased prevalence of anaemia ${ }^{25}$ and EPO levels have been demonstrated to fall in this setting. ${ }^{62}$

\section{Iron therapy in clinical practice}

In COPD, patients with iron deficiency are more hypoxaemic even though they do not have significantly worse airflow limitation. ${ }^{63}$ Beyond erythropoiesis, a role for iron replacement in lung disease is supported by the role iron has in various processes including its fundamental role in mitochondrial respiration and energy processing, a structural role in proteins such as myoglobin and in the response to infection. It has been demonstrated that iron deficiency results in exaggerated hypoxic pulmonary hypertension that is reversed by subsequent iron administration $^{64} 65$ and studies evaluating the potential benefit of iron replacement in PAH are currently running. Although routinely used for iron replacement, oral iron supplementation is limited by absorption and gastrointestinal side effects. Intravenous iron is an established therapy in heart failure and continues to be studied in various populations. The FAIR-HF Trial, ${ }^{66} 67$ a multicentre, randomised, double-blind, placebo-controlled trial of intravenous ferric carboxymaltose for symptomatic patients with heart failure and iron deficiency anaemia, found a 1 class improvement in New York Heart Association was 2.40-fold more likely to occur $(95 \%$ CI 1.55 to 3.71$)$ in the treatment group which demonstrated a change in 6-min walk test distance of $35 \pm 8 \mathrm{~m}, \mathrm{p}<0.001$ at week 24 . Similar results were obtained from the CONFIRM-HF study. ${ }^{68}$ In COPD, there are presently no reported data from randomised controlled trials investigating the effect of either oral or intravenous iron, but two studies evaluating intravenous iron are presently recruiting according to clinicaltrials.gov (NCT NCT03050424 and NCT02416778). In respiratory populations, iron deficiency has been associated with reduced aerobic capacity and an impaired response to pulmonary rehabilitation in COPD ${ }^{69}$ and mortality in the setting of tuberculosis infection. ${ }^{35}$

We are not aware of any trials investigating iron replacement in patients with IPF or bronchiectasis, although there have been small studies in CF where we note that iron chelation has been proposed as a therapeutic option in patients colonised with Pseudomonas aeruginosa through a proposed beneficial effect on Pseudomonas cell-cell communication. ${ }^{7071}$ As in COPD, in the setting of inflammation, an impaired erythropoietic response to hypoxaemia has been described in adult patients with $\mathrm{CF}^{27} \mathrm{In}$ one study, a 3-month course of oral iron did not increase $\mathrm{Hb}$ in a subgroup of patients with $\mathrm{CF}$ and functional iron deficiency. Absorption and compartmentalisation of iron are likely to be relevant and this concept is supported by a very small case series of adult patients with $\mathrm{CF}$, who when given intravenous iron for anaemia refractory to oral iron, demonstrated a significant rise in $\mathrm{Hb}$ concentration and mean corpuscular volume within days of therapy. ${ }^{72}$ These findings are consistent with suppression of iron 
absorption by hepcidin. Although commonly used in clinical practice and generally regarded as safe, exogenous iron compartmentalising to the tissues and contributing to oxidative stress-related tissue damage may be a concern in chronic lung disease. ${ }^{73}$

\section{Novel treatment options}

The only disease area where correction of anaemia of chronic disease has been extensively studied is in chronic kidney disease (CKD) in response to recombinant human erythropoietin (rhEPO) and its analogues. Even in the presence of normal lung physiology, therapy in CKD has been demonstrated to improve exercise tolerance, HRQoL, cerebration and left ventricular hypertrophy. ${ }^{74}$ There is also evidence to show a beneficial effect in chronic heart failure with improved exercise tolerance, decreased oxygen utilisation on exercise, improved renal function, decreased brain natriuretic peptide and reduced hospitalisation; ${ }^{75}$ however, concerns over the deleterious effects of increased EPO levels and adverse cardiovascular events have led to a lack of enthusiasm for use of EPO in chronic heart failure and more conservative usage in CKD. ${ }^{74}{ }^{76}$ Treatment of anaemia of CKD with rhEPO is associated with increased cardiovascular risk which is postulated to be related to the associated increases in EPO exposure. ${ }^{77}$ It is unclear if this risk can be attributed solely to EPO exposure as opposed to targeted or achieved $\mathrm{Hb}$, the specific relevance of the absolute $\mathrm{Hb}, \mathrm{Hb}$ change, the rate of $\mathrm{Hb}$ change or the EPO levels that occur in dosing patients with rhEPO. Given that normal $\mathrm{Hb}$ levels are protective and other therapies increase $\mathrm{Hb}$ without risk, the supraphysiological levels of EPO and impact on sympathetic drive seem inherently most relevant but this is as yet unproven. Subsequently, for CKD, US Prescribing Information for all currently approved erythropoietin stimulating agents (ESAs) contains a Boxed Warning and European labels contain warnings that patients experienced greater risk for death, serious adverse cardiovascular reactions and stroke when administered ESAs to target a $\mathrm{Hb}$ level of greater than $11 \mathrm{~g} / \mathrm{dL}^{61}$

While ESAs have not been generally used in lung disease outside the setting of significant concomitant renal disease, iron therapy is commonly used. Furthermore, $\mathrm{Hb}$ in the normal range is associated with better survival and reduced breathlessness, improved exercise performance and HRQoL. It is expected that anaemic patients with chronic lung disease will benefit from the potential multimodal benefits of having improved $\mathrm{Hb}$ levels and improved $\mathrm{O}_{2}$ delivery to the tissues and that in this context treating anaemia of chronic disease in patients with chronic lung disease is a different paradigm to other diseases, especially when it is considered that beyond iron replacement, there are no established relevant treatment options in these patients. Few interventional studies have been conducted to assess the treatment of anaemia in chronic lung disease. Several small studies have been conducted which have demonstrated the potential benefit of this approach with reduced ventilatory requirements following red blood cell transfusion to increase $\mathrm{Hb}$ from 9.8 to $12.3 \mathrm{~g} / \mathrm{dL}^{78}$ and successfully weaning patients from ventilatory support when their $\mathrm{Hb}$ values were increased to within the normal range $(12 \mathrm{~g} / \mathrm{dL}) \cdot{ }^{79}$ A small uncontrolled study demonstrated that intravenous iron and ESA resulted in increases in $\mathrm{Hb}$ which directly correlated with improvements in dyspnoea in anaemic patients with COPD ${ }^{80}$ Although it is not possible to differentiate the effect of iron and ESA in the latter study, overall, these studies suggest a direct correlation between improvements in $\mathrm{Hb}$ and physiological parameters through improved circulating oxygen content in patients with chronic lung disease which should lead to symptomatic benefit and potentially impact longer term outcomes. Indeed, it is possible that the potential benefits to be derived from improved $\mathrm{Hb}$ (through oxygen delivery) and iron regulation (through improved mitochondrial function and pulmonary vascular tone) may be additive.

Small molecules which inhibit hypoxia-inducible factor (HIF) prolyl-4-hydroxylases, preventing the breakdown of the HIF transcription factor, are currently in development. In preclinical studies, HIF stabilisation results in the accumulation of HIF and upregulation of HIF-responsive genes. ${ }^{61}$ This biological activity simulates multiple components of the natural tissue response to hypoxia, including erythropoiesis, angiogenesis, immune modulation and enhanced cell survival. Agents targeting HIF stabilisation have been shown to induce endogenous EPO production and improve markers of iron metabolism, resulting in erythropoiesis and increased $\mathrm{Hb}$ levels in subjects with anaemia associated with $\mathrm{CKD}^{81}$ and also in other populations such as patients with peripheral arterial disease. ${ }^{82}$ These molecules may be of value in chronic lung disease where a dysregulated EPO response may revert to a more functional response in the setting of improved longer term iron regulation through HIF stabilisation. Through this mechanism and improved tissue $\mathrm{O}_{2}$ delivery, chronic EPO levels may be lower and more stable in addition to more functional. Investigation of agents targeting HIF-PHIs (prolyl hydroxylase inhibitors) for the treatment of anaemia associated with CKD have progressed into Phase III clinical studies, including large cardiovascular outcome trials. For the treatment of anaemia of CKD, HIF stabilisation has the potential to provide similar or better efficacy to approved therapies with the potential for an improved safety profile, most notably compared with rhEPO and conventional ESAs. Adverse effects that were initially observed with ESAs included elevated blood pressure, seizures and a high rate of thrombotic events, although approaches to slowly increase the haematocrit seem to minimise these problems, concerns around the development of immune reactions to developing antibodies and cardiovascular events remain. ${ }^{83}$ The risks associated with rhEPO may hypothetically be found with HIF-PHIs since they also raise 
$\mathrm{Hb}$ and EPO levels, although the mechanism of action of increasing red blood cell mass is not solely mediated through EPO, and EPO is not raised to the supraphysiological levels observed following administration of exogenous rhEPO injection. Hypothetical risks for malignancy and pulmonary hypertension have been suggested by findings in patients with naturally occurring mutations that result in HIF upregulation and these may be particularly relevant in chronic lung disease where patients are already predisposed to these afflictions. ${ }^{83} 84$ Furthermore, beyond the relevance of iron in innate immunity, animal and cell studies indicate a potential for HIF upregulation to increase the risk of infection. ${ }^{85-87}$ Despite these considerations, HIF-PHIs have been considered safe and well tolerated in clinical studies thus far and outcome studies currently underway will add further to the longer term safety experience with manipulating HIF as a therapeutic strategy. ${ }^{81}$ Given pulmonary hypertension may deteriorate under strain in chronic lung disease, this requires further consideration. The key driver for the development of pulmonary hypertension in chronic lung disease is hypoxia, subsequently improved $\mathrm{O}_{2}$ delivery (through improved $\mathrm{Hb}$ ) and improved iron availability mediated by HIF stabilisation could potentially ameliorate pulmonary hypertension. Anaemia in the setting of pulmonary hypertension and COPD is associated with a greater rate of deterioration in exercise capacity, hypoxaemia, quality of life and acute exacerbations. ${ }^{88}$ Recent clinical experience indicates that HIF-PHI can increase EPO levels at very small doses where drug exposure may be largely or even entirely confined to the liver and kidneys (EPO-producing organs) ${ }^{6183}$ Therefore, it is possible the EPO-producing potential of these agents can be realised without direct effects on the lung vasculature.

Given the experience with ESAs, there may be reservations about targeting $\mathrm{Hb}$ levels $>11 \mathrm{~g} / \mathrm{dL}$; however, considering physiological and clinical differences, it may not be appropriate to extrapolate considerations from other populations to patients with chronic lung disease. As with CKD, patients with chronic lung disease are predisposed to increased CV morbidity and mortality. The current limits (to not start rhEPO unless $\mathrm{Hb}<10 \mathrm{~g}$ / $\mathrm{dL}$ ) with rhEPO treatment in CKD where there is not a primary driver for hypoxia beyond the anaemia itself make development of rhEPO in the chronic lung disease population challenging given that most of the population are not anaemic. ${ }^{1489}$ In this regard, it is relevant that the benefit:risk considerations in chronic lung disease are different from CKD, given the key synergistic impacts of impaired pulmonary gas exchange and $\mathrm{O}_{2}$ carriage in this population where there is no established treatment option for anaemia of chronic disease. Clinical studies have demonstrated that treatment with HIF-PHIs is associated with plasma EPO levels that remain within the physiological range for the CKD patient population, ${ }^{90}$ and hence risks associated with supraphysiological EPO levels may be significantly lower. Improved $\mathrm{O}_{2}$ content through improved $\mathrm{Hb}$ may improve cardiovascular outcomes in chronic lung disease at higher $\mathrm{Hb}$ levels, given the increased cardiac risk, especially during periods of strain such as hospitalisations that are associated with hypoxia and an increased risk of anaemia. ${ }^{91}$ Consistent with the variable impact of impaired $\mathrm{O}_{2}$ delivery through reduced $\mathrm{Hb}$ in different populations, despite potential safety concerns in CKD ${ }^{92}$ a meta-analysis has demonstrated a reduction in hospitalisations in chronic heart failure ${ }^{93}$ in the absence of any mortality benefit with rhEPO in this population. ${ }^{94}$

In conclusion, anaemia and dysregulated iron metabolism are prevalent in chronic lung disease, and in the setting of impaired $\mathrm{O}_{2}$ delivery in patients who have a limited ability to compensate, there is associated morbidity and mortality. Therapies used in other disease areas may have particular benefits in this population. Given changes in standards of care, clinical features in chronic lung disease are evolving and newer therapies may provide opportunities to deliver improved outcomes in chronic lung disease. Given differences in populations and the ongoing morbidity and mortality burden, studies in chronic lung disease are warranted to confirm any benefit to treating anaemia and dysregulated iron metabolism and to mitigate any theoretical safety risks that extend from the literature and other populations.

Acknowledgements The authors would like to thank Professor Sir Peter Ratcliffe (Nuffield Department of Medicine, Oxford) for reading and commenting on this State of the art review.

Contributors The review was first drafted and developed by MSP and SJP with subsequent contribution from all authors.

Funding The authors have not declared a specific grant for this research from any funding agency in the public, commercial or not-for-profit sectors.

Disclaimer The views expressed by Elizabeth McKie, an employee of GlaxoSmithKline, are her own and may not necessarily express or represent the opinions of GlaxoSmithKline.

Competing interests MSP is an AstraZeneca employee and former GlaxoSmithKline (GSK) employee, EM is a GSK employee and shareholder and SJP is a GSK shareholder and a Sanofi employee. MCS reports personal fees from GSK, Boerhinger Ingelheim and Nutricia outside of the submitted work and MIP has received grants from GSK outside of the submitted work.

Patient consent for publication Not required.

Provenance and peer review Not commissioned; internally peer reviewed. Data availability statement All data relevant to the study are included in the article or uploaded as supplementary information.

Open access This is an open access article distributed in accordance with the Creative Commons Attribution Non Commercial (CC BY-NC 4.0) license, which permits others to distribute, remix, adapt, build upon this work non-commercially, and license their derivative works on different terms, provided the original work is properly cited, appropriate credit is given, any changes made indicated, and the use is non-commercial. See: http://creativecommons.org/licenses/by-nc/4.0/.

\section{REFERENCES}

1. Jolley CJ, Luo Y-M, Steier J, et al. Neural respiratory drive in healthy subjects and in COPD. Eur Respir J 2009;33:289-97.

2. Maclntyre NR. Tissue hypoxia: implications for the respiratory clinician. Respir Care 2014;59:1590-6.

3. Ward J. Oxygen delivery and demand. Surgery 2006;24:354-60.

4. Polkey MI, Hawkins P, Kyroussis D, et al. Inspiratory pressure support prolongs exercise induced lactataemia in severe COPD. Thorax 2000;55:547-9.

5. Global Initiative for Chronic Obstructive Lung Disease. Global strategy for the diagnosis, management and prevention of COPD; 2017. 
6. Lozano R, Naghavi M, Foreman K, et al. Global and regional mortality from 235 causes of death for 20 age groups in 1990 and 2010: a systematic analysis for the global burden of disease study 2010. Lancet 2012;380:2095-128.

7. McNarry MA, Harrison NK, Withers T, et al. Pulmonary oxygen uptake and muscle deoxygenation kinetics during heavy intensity cycling exercise in patients with emphysema and idiopathic pulmonary fibrosis. BMC Pulm Med 2017;17:26.

8. Habler OP, Messmer KF. The physiology of oxygen transport. Transfus Sci 1997;18:425-35

9. Knower MT, Dunagan DP, Adair NE, et al. Baseline oxygen saturation predicts exercise desaturation below prescription threshold in patients with chronic obstructive pulmonary disease. Arch Intern Med 2001:161:732-6.

10. Lacasse $\mathrm{Y}$, Sériès $\mathrm{F}$, Vujovic-Zotovic $\mathrm{N}$, et al. Evaluating nocturnal oxygen desaturation in COPDr-evised. Respir Med 2011;105:1331-7.

11. Luo Y-M, He B-T, Wu Y-X, et al. Neural respiratory drive and ventilation in patients with chronic obstructive pulmonary disease during sleep. Am J Respir Crit Care Med 2014;190:227-9.

12. Boutou AK, Stanopoulos I, Pitsiou GG, et al. Anemia of chronic disease in chronic obstructive pulmonary disease: a case-control study of cardiopulmonary exercise responses. Respiration 2011:82:237-45.

13. Chambellan A, Chailleux E, Similowski T, et al. Prognostic value of the hematocrit in patients with severe COPD receiving long-term oxygen therapy. Chest 2005;128:1201-8

14. Cote C, Zilberberg MD, Mody SH, et al. Haemoglobin level and its clinical impact in a cohort of patients with COPD. Eur Respir J 2007;29:923-9.

15. Haidl P, Clement C, Wiese C, et al. Long-Term oxygen therapy stops the natural decline of endurance in COPD patients with reversible hypercapnia. Respiration 2004;71:342-7.

16. Continuous or nocturnal oxygen therapy in hypoxemic chronic obstructive lung disease: a clinical trial. nocturnal oxygen therapy trial group. Ann Intern Med 1980;93:391-8.

17. Long term domiciliary oxygen therapy in chronic hypoxic cor pulmonale complicating chronic bronchitis and emphysema. Report of the medical Research Council Working Party. Lancet 1981;1:681-6.

18. Somfay A, Porszasz J, Lee SM, et al. Dose-response effect of oxygen on hyperinflation and exercise endurance in nonhypoxaemic COPD patients. Eur Respir J 2001;18:77-84.

19. Cranston JM, Crockett A, Moss J, et al. Domiciliary oxygen for chronic obstructive pulmonary disease. Cochrane Database Syst Rev 2005;14:CD001744.

20. Albert RK, Au DH, Blackford AL, et al. A randomized trial of longterm oxygen for COPD with moderate desaturation. N Engl J Med 2016;375:1617-27.

21. Panos RJ, Eschenbacher W. Exertional desaturation in patients with chronic obstructive pulmonary disease. COPD 2009;6:478-87.

22. Pépin J-L, Barjhoux CE, Deschaux C, et al. Long-term oxygen therapy at home. Chest 1996;109:1144-50.

23. Morrison D, Skwarski K, MacNee W. Review of the prescription of domiciliary long term oxygen therapy in Scotland. Thorax 1995;50:1103-5.

24. Hoiland RL, Bain AR, Rieger MG, et al. Hypoxemia, oxygen content, and the regulation of cerebral blood flow. Am J Physiol Regul Integr Comp Physiol 2016;310:R398-R413.

25. Silverberg DS, Mor R, Weu MT, et al. Anemia and iron deficiency in COPD patients: prevalence and the effects of correction of the anemia with erythropoiesis stimulating agents and intravenous iron. BMC Pulm Med 2014;14:24.

26. Martinez-Rivera C, Portillo K, Muñoz-Ferrer A, et al. Anemia is a mortality predictor in hospitalized patients for COPD exacerbation. COPD 2012;9:243-50.

27. Fischer R, Simmerlein R, Huber RM, et al. Lung disease severity, chronic inflammation, iron deficiency, and erythropoietin response in adults with cystic fibrosis. Pediatr Pulmonol 2007;42:1193-7.

28. von Drygalski A, Biller J. Anemia in cystic fibrosis: incidence, mechanisms, and association with pulmonary function and vitamin deficiency. Nutr Clin Pract 2008;23:557-63.

29. Rhodes CJ, Wharton J, Howard L, et al. Iron deficiency in pulmonary arterial hypertension: a potential therapeutic target. Eur Respir J 2011;38:1453-60.

30. Reid DW, Withers NJ, Francis L, et al. Iron deficiency in cystic fibrosis: relationship to lung disease severity and chronic Pseudomonas aeruginosa infection. Chest 2002;121:48-54.

31. Cook JD, Dassenko S, Skikne BS. Serum transferrin receptor as an index of iron absorption. Br J Haematol 1990;75:603-9.
32. Gifford AH, Miller SD, Jackson BP, et al. Iron and CF-related anemia: expanding clinical and biochemical relationships. Pediatr Pulmonol 2011;46:160-5.

33. Kollert F, Tippelt A, Müller C, et al. Hemoglobin levels above anemia thresholds are maximally predictive for long-term survival in COPD with chronic respiratory failure. Respir Care 2013;58:1204-12.

34. Krasuski RA, Hart SA, Smith B, et al. Association of anemia and long-term survival in patients with pulmonary hypertension. Int $J$ Cardiol 2011:150:291-5.

35. Isanaka S, Mugusi F, Urassa W, et al. Iron deficiency and anemia predict mortality in patients with tuberculosis. $J$ Nutr 2012;142:350-7.

36. Putcha N, Fawzy A, Paul GG, et al. Anemia and adverse outcomes in a chronic obstructive pulmonary disease population with a high burden of comorbidities. An analysis from SPIROMICS. Ann Am Thorac Soc 2018;15:710-7.

37. Ferrari M, Manea L, Anton K, et al. Anemia and hemoglobin serum levels are associated with exercise capacity and quality of life in chronic obstructive pulmonary disease. BMC Pulm Med 2015;15:58

38. Heinicke K, Heinicke I, Schmidt W, et al. A three-week traditional altitude training increases hemoglobin mass and red cell volume in elite biathlon athletes. Int J Sports Med 2005;26:350-5.

39. Lobigs LM, Sharpe K, Garvican-Lewis LA, et al. The athlete's hematological response to hypoxia: a meta-analysis on the influence of altitude exposure on key biomarkers of erythropoiesis. $A m \mathrm{~J}$ Hematol 2018;93:74-83.

40. Broberg CS, Bax BE, Okonko DO, et al. Blood viscosity and its relationship to iron deficiency, symptoms, and exercise capacity in adults with cyanotic congenital heart disease. J Am Coll Cardiol 2006;48:356-65

41. Hoepers ATdeC, Menezes MM, Fröde TS. Systematic review of anaemia and inflammatory markers in chronic obstructive pulmonary disease. Clin Exp Pharmacol Physiol 2015;42:231-9.

42. Armitage AE, Eddowes LA, Gileadi $U$, et al. Hepcidin regulation by innate immune and infectious stimuli. Blood 2011:118:4129-39.

43. Pond MN, Morton AM, Conway SP. Functional iron deficiency in adults with cystic fibrosis. Respir Med 1996;90:409-13.

44. Taniguchi S, Dai CH, Price JO, et al. Interferon gamma downregulates stem cell factor and erythropoietin receptors but not insulin-like growth factor-I receptors in human erythroid colonyforming cells. Blood 1997;90:2244-52.

45. Wrighting DM, Andrews NC. Interleukin-6 induces hepcidin expression through STAT3. Blood 2006;108:3204-9.

46. Nemeth E, Rivera S, Gabayan V, et al. II-6 mediates hypoferremia of inflammation by inducing the synthesis of the iron regulatory hormone hepcidin. J Clin Invest 2004;113:1271-6.

47. Ferrucci L, Semba RD, Guralnik JM, et al. Proinflammatory state, hepcidin, and anemia in older persons. Blood 2010;115:3810-6.

48. Andreas S, Herrmann-Lingen C, Raupach T, et al. Angiotensin II blockers in obstructive pulmonary disease: a randomised controlled trial. Eur Respir J 2006;27:972-9.

49. Vlahakos DV, Kosmas EN, Dimopoulou I, et al. Association between activation of the renin-angiotensin system and secondary erythrocytosis in patients with chronic obstructive pulmonary disease. Am J Med 1999;106:158-64.

50. Babitt JL, Lin HY. Mechanisms of anemia in CKD. J Am Soc Nephrol 2012;23:1631-4.

51. Incalzi RA, Corsonello $\mathrm{A}$, Pedone $\mathrm{C}$, et al. Chronic renal failure: a neglected comorbidity of COPD. Chest 2010;137:831-7.

52. Oren R, Beeri M, Hubert $A$, et al. Effect of theophylline on erythrocytosis in chronic obstructive pulmonary disease. Arch Intern Med 1997;157:1474-8

53. Tsantes AE, Tassiopoulos ST, Papadhimitriou SI, et al. Theophylline treatment may adversely affect the anoxia-induced erythropoietic response without suppressing erythropoietin production. Eur J Clin Pharmacol 2003;59:379-83.

54. Balasubramanian V, Naing S. Hypogonadism in chronic obstructive pulmonary disease: incidence and effects. Curr Opin Pulm Med 2012;18:112-7.

55. Obase Y, Mouri K, Shimizu H, et al. Nutritional deficits in elderly smokers with respiratory symptoms that do not fulfill the criteria for COPD. Int J Chron Obstruct Pulmon Dis 2011;6:679-83.

56. Fimognari FL, Loffredo L, Di Simone S, et al. Hyperhomocysteinaemia and poor vitamin B status in chronic obstructive pulmonary disease. Nutr Metab Cardiovasc Dis 2009;19:654-9.

57. Ferrucci L, Guralnik JM, Woodman RC, et al. Proinflammatory state and circulating erythropoietin in persons with and without anemia. Am J Med 2005;118:1288

58. Tassiopoulos S, Kontos A, Konstantopoulos K, et al. Erythropoietic response to hypoxaemia in diffuse idiopathic pulmonary fibrosis, 
as opposed to chronic obstructive pulmonary disease. Respir Med 2001;95:471-5.

59. Markoulaki D, Kostikas K, Papatheodorou G, et al. Hemoglobin, erythropoietin and systemic inflammation in exacerbations of chronic obstructive pulmonary disease. Eur J Intern Med 2011;22:103-7.

60. Brigandi RA, Johnson B, Oei C, et al. A novel hypoxia-inducible factor-prolyl hydroxylase inhibitor (GSK1278863) for anemia in CKD: a 28-day, phase 2A randomized trial. Am J Kidney Dis 2016;67:861-71.

61. Gupta N, Wish JB. Hypoxia-inducible factor prolyl hydroxylase inhibitors: a potential new treatment for anemia in patients with CKD. Am J Kidney Dis 2017;69:815-26.

62. Sala E, Balaguer C, Villena C, et al. Low erythropoietin plasma levels during exacerbations of COPD. Respiration 2010;80:190-7.

63. Nickol AH, Frise MC, Cheng H-Y, et al. A cross-sectional study of the prevalence and associations of iron deficiency in a cohort of patients with chronic obstructive pulmonary disease. BMJ Open 2015;5:e007911.

64. Frise $\mathrm{MC}$, Cheng $\mathrm{H}-\mathrm{Y}$, Nickol $\mathrm{AH}$, et al. Clinical iron deficiency disturbs normal human responses to hypoxia. $J$ Clin Invest 2016:126:2139-50.

65. Smith TG, Talbot NP, Privat C, et al. Effects of iron supplementation and depletion on hypoxic pulmonary hypertension: two randomized controlled trials. JAMA 2009;302:1444-50.

66. Ponikowski P, Filippatos G, Colet JC, et al. The impact of intravenous ferric carboxymaltose on renal function: an analysis of the FAIR-HF study. Eur J Heart Fail 2015;17:329-39.

67. Anker SD, Comin Colet J, Filippatos G, et al. Ferric carboxymaltose in patients with heart failure and iron deficiency. $N$ Engl $J$ Med 2009;361:2436-48.

68. Ponikowski P, van Veldhuisen DJ, Comin-Colet $\mathrm{J}$, et al. Beneficial effects of long-term intravenous iron therapy with ferric carboxymaltose in patients with symptomatic heart failure and iron deficiencyt. Eur Heart J 2015;36:657-68.

69. Barberan-Garcia A, Rodríguez DA, Blanco I, et al. Non-Anaemic iron deficiency impairs response to pulmonary rehabilitation in COPD. Respirology 2015;20:1089-95.

70. Smith DJ, Lamont IL, Anderson GJ, et al. Targeting iron uptake to control Pseudomonas aeruginosa infections in cystic fibrosis. Eur Respir J 2013:42:1723-36.

71. Aali M, Caldwell A, House K, et al. Iron chelation as novel treatment for lung inflammation in cystic fibrosis. Med Hypotheses 2017; 104:86-8.

72. Hoo ZH, Wildman MJ. Intravenous iron among cystic fibrosis patients. J Cyst Fibros 2012;11:560-2.

73. Cloonan SM, Mumby S, Adcock IM, et al. The Iron-Y of iron overload and iron deficiency in chronic obstructive pulmonary disease. $\mathrm{Am} \mathrm{J}$ Respir Crit Care Med 2017:196:1103-12.

74. Teehan G, Benz RL. An update on the controversies in anemia management in chronic kidney disease: lessons learned and lost. Anemia 2011;2011:623673

75. Palazzuoli A, Silverberg D, lovine F, et al. Erythropoietin improves anemia exercise tolerance and renal function and reduces B-type natriuretic peptide and hospitalization in patients with heart failure and anemia. Am Heart J 2006;152:1096
76. Unger EF, Thompson AM, Blank MJ, et al. Erythropoiesis-stimulating agents-time for a reevaluation. N Engl J Med 2010;362:189-92.

77. Szczech LA, Barnhart HX, Inrig JK, et al. Secondary analysis of the CHOIR trial epoetin-alpha dose and achieved hemoglobin outcomes. Kidney Int 2008;74:791-8.

78. Schönhofer B, Wenzel M, Geibel M, et al. Blood transfusion and lung function in chronically anemic patients with severe chronic obstructive pulmonary disease. Crit Care Med 1998;26:1824-8.

79. Schönhofer B, Böhrer H, Köhler D. Blood transfusion facilitating difficult weaning from the ventilator. Anaesthesia 1998;53:181-4.

80. Silverberg DS. The role of erythropoiesis stimulating agents and intravenous (IV) iron in the cardio renal anemia syndrome. Heart Fail Rev 2011;16:609-14.

81. Wyatt CM, Drüeke TB. Hif stabilization by prolyl hydroxylase inhibitors for the treatment of anemia in chronic kidney disease. Kidney Int 2016;90:923-5.

82. Haase VH. Therapeutic targeting of the HIF oxygen-sensing pathway: lessons learned from clinical studies. Exp Cell Res 2017;356:160-5.

83. Maxwell PH, Eckardt K-U. Hif prolyl hydroxylase inhibitors for the treatment of renal anaemia and beyond. Nat Rev Nephrol 2016:12:157-68.

84. Dunham-Snary KJ, Wu D, Sykes EA, et al. Hypoxic pulmonary vasoconstriction: from molecular mechanisms to medicine. Chest 2017:151:181-92.

85. Cassat JE, Skaar EP. Iron in infection and immunity. Cell Host Microbe 2013;13:509-19.

86. Schaible B, Rodriguez J, Garcia A, et al. Hypoxia reduces the pathogenicity of pseudomonas aeruginosa by decreasing the expression of multiple virulence factors. J Infect Dis 2017;215:1459-67.

87. Polke M, Seiler F, Lepper PM, et al. Hypoxia and the hypoxiaregulated transcription factor HIF-1 $\alpha$ suppress the host defence of airway epithelial cells. Innate Immun 2017;23:373-80.

88. Xiong $\mathrm{W}, \mathrm{Xu} \mathrm{M}$, Pudasaini $\mathrm{B}$, et al. The influence of anemia on oneyear exacerbation rate of patients with COPD-PH. BMC Pulm Med 2018;18:143

89. Boutou AK, Karrar S, Hopkinson NS, et al. Anemia and survival in chronic obstructive pulmonary disease: a dichotomous rather than a continuous predictor. Respiration 2013;85:126-31.

90. Holdstock L, Meadowcroft AM, Maier R, et al. Four-Week studies of oral hypoxia-inducible factor-prolyl hydroxylase inhibitor GSK1278863 for treatment of anemia. J Am Soc Nephrol 2016;27.

91. Singanayagam A, Schembri S, Chalmers JD. Predictors of mortality in hospitalized adults with acute exacerbation of chronic obstructive pulmonary disease. A systematic review and meta-analysis. Ann Am Thorac Soc 2013:10:81-9.

92. Singh AK, Szczech L, Tang KL, et al. Correction of anemia with epoetin alfa in chronic kidney disease. N Engl $J$ Med 2006;355:2085-98

93. van der Meer P, Groenveld HF, Januzzi JL, et al. Erythropoietin treatment in patients with chronic heart failure: a meta-analysis. Heart 2009;95:1309-14.

94. Swedberg K, Young JB, Anand IS, et al. Treatment of anemia with darbepoetin alfa in systolic heart failure. $N$ Engl $\mathrm{J} \mathrm{Med}$ 2013;368:1210-9. 